University of Wollongong

Research Online

Australian Institute for Innovative Materials -

Papers

Australian Institute for Innovative Materials

$1-1-2013$

\title{
The electrochemical properties of high-capacity sulfur/reduced graphene oxide with different electrolyte systems
}

\author{
Yunxiao Wang \\ University of Wollongong, yw708@uowmail.edu.au \\ Shulei Chou \\ University of Wollongong, shulei@uow.edu.au \\ Hua-Kun Liu \\ University of Wollongong, hua@uow.edu.au \\ SX. Dou \\ University of Wollongong, shi@uow.edu.au
}

Follow this and additional works at: https://ro.uow.edu.au/aiimpapers

Part of the Engineering Commons, and the Physical Sciences and Mathematics Commons 


\title{
The electrochemical properties of high-capacity sulfur/reduced graphene oxide with different electrolyte systems
}

\author{
Abstract \\ The lithium/sulfur battery is a promising electrochemical system with high capacity, which is well-known \\ to undergo a complex multistep reaction during the discharge process. Two types of electrolytes \\ including poly (ethylene glycol) dimethyl ether (PEGDME)-based and 1.3 - dioxolane (DOL)/ \\ dimethoxyethane (DME)-based electrolytes were investigated here. Furthermore, LiNO3 additive was \\ introduced into the electrolyte in order to effectively eliminate the overcharge effect. The lithium sulfur \\ battery with 1.0 M LiN(CF3SO2)2 in PEGME with $0.1 \mathrm{M}$ LiNo3 shows highly stable reversible capacity of \\ $624.8 \mathrm{mAh} \mathrm{g}-1$ after 200 cycles and improved average coulombic efficiency of 98 percent.
}

\section{Keywords}

high, properties, systems, electrolyte, different, oxide, graphene, reduced, sulfur, capacity, electrochemical

\section{Disciplines}

Engineering | Physical Sciences and Mathematics

\section{Publication Details}

Wang, Y., Chou, S., Liu, H. K. \& Dou, S. Xue. (2013). The electrochemical properties of high-capacity sulfur/ reduced graphene oxide with different electrolyte systems. Journal of Power Sources, 244 (December), 240-245. 


\title{
The electrochemical properties of high-capacity sulfur/reduced graphene oxide with different electrolyte systems
}

\author{
Yun-Xiao Wang, Shu-Lei Chou, ${ }^{*}$ Hua-Kun Liu, Shi-Xue Dou \\ Institute for Superconducting \& Electronic Materials (ISEM), Innovation Campus, \\ University of Wollongong, Wollongong, NSW, 2519, Australia.
}

\begin{abstract}
The lithium/sulfur battery is a promising electrochemical system with high capacity, which is well-known to undergo a complex multistep reaction during the discharge process. Two types of electrolytes including poly(ethylene glycol) dimethyl ether (PEGDME)-based and 1,3-dioxolane (DOL)/dimethoxyethane (DME)-based electrolytes were investigated here. Furthermore, $\mathrm{LiNO}_{3}$ additive was introduced into the electrolyte in order to effectively eliminate the overcharge effect. The lithium sulfur battery with $1.0 \mathrm{M} \mathrm{LiN}\left(\mathrm{CF}_{3} \mathrm{SO}_{2}\right)_{2}$ in $\mathrm{PEGDME}$ with $0.1 \mathrm{M} \mathrm{LiNO}_{3}$ shows highly stable reversible capacity of $624.8 \mathrm{mAh} \mathrm{g}^{-1}$ after 200 cycles and improved average coulombic efficiency of $98 \%$.
\end{abstract}

Keywords: electrolyte; $\mathrm{LiNO}_{3}$ additive; lithium-sulfur battery; S/RGO cathode

*Corresponding author. Tel.: +61-2-4298-1405; Fax: +61-2-4221-5731

E-mail: shulei@uow.edu.au 


\section{Introduction}

In terms of the high energy demand for many practical applications, researches on energy-storage systems currently focused on development of novel materials for rechargeable lithium-ion batteries (LIB) [1-4]. However, the energy density of LIB is limited to the level of $100-150 \mathrm{Wh} / \mathrm{kg}$ as a result of low capacity of all cathodes. In contrast, lithium-sulfur battery may have great potential to become next-generation batteries for high energy density applications [5.6].

Sulfur cathode possesses numerous overwhelming advantages, including almost the highest theoretical capacity $\left(1675 \mathrm{mAh} \mathrm{g}^{-1}\right)$ and the highest theoretical specific energy (2600 $\mathrm{Wh} \mathrm{kg}^{-1}$ ), abundant natural resources, low equivalent weight, low cost and non-toxicity [7-10]. Lithium-Sulfur battery therefore has significant potential to be used in next-generation batteries with high capacity and energy density. Nevertheless, a number of complex problems need to be overcome to realize its commercial potential [11-13]. One of critical shortcoming is that sulfur has the insulating nature. It is inevitable that the cathode for Li-S battery must contain a conductive additive, which ensures more efficient electronic contact of sulfur. The common additives are carbonaeous materials, including mesoporous carbon [5], carbon nanotubes [14], hollow carbon nanofibers [15], and graphene [6,16]. Compared with reduced graphene oxide (RGO) fabricated by Hummers' method [17], the synthesis process of other carbon matrixes are much more complicated and costly. From the commercial viewpoint, RGO offers exceptional advantages, owing to its high productivity and low

cost. Moreover, its nanostructures with significant disorder, expanded interlayer 
spacing and numerous active defects can effectively trap the active materials. This has been proven to improve the electrochemical performance of Li-S batteries in the previous study [16]. Furthermore, the Li-S battery is based on the reversible redox reaction between lithium and sulfur, which contains several intermediate reactions with lithium polysulfides $\left(\mathrm{Li}_{2} \mathrm{~S}_{\mathrm{n}}\right)$ as intermediate products during the discharge process [18]. $\mathrm{Li}_{2} \mathrm{~S}_{\mathrm{n}}$ would hinder the in-depth discharge of sulfur because of its insulating properties and variable valence, resulting in low utilization of sulfur and low rate capability. Exploiting polar organic solvents, however, such as 1,3-dioxolane (DOL), dimethoxyethane (DME), and tetra(ethylene glycol) dimethyl ether (TEGDME), can alleviate this problem by dissolve polysufides to some extent, but at the cost of inducing the internal shuttle phenomenon $[19,20]$, causing fast capacity fading and severely low Coulombic efficiency. Much effort is being devoted to alleviating this phenomenon by modifying the surface of Li anode, especially by inducing $\mathrm{LiNO}_{3}$ additive in the electrolyte can form an in-situ protective surface film on the lithium foil [21-23]. Therefore, it is well recognized that the electrolyte plays a crucial role in the realization of $\mathrm{Li} / \mathrm{S}$ applications.

In this communication, in view of the promising properties of $\mathrm{S} / \mathrm{RGO}$ composite with $60 \mathrm{wt} \%$ sulfur, as demonstrated by our previous work [16], two kinds of electrolyte systems, with dimethoxyethane (DME)/dioxolane (DOL) and poly(ethylene glycol) dimethyl ether (PEGDME) as solvents, are utilized to determine their effects on $\mathrm{S} / \mathrm{RGO}$ electrochemical performance. Moreover, the function of $\mathrm{LiNO}_{3}$ additive in these electrolytes was investigated. 


\section{Experimental}

Graphite oxide was prepared from natural graphite by the modified Hummers' method [17]. Graphite powder $(2 \mathrm{~g})$ was added into $46 \mathrm{~mL}$ concentrated $\mathrm{H}_{2} \mathrm{SO}_{4}$ then 1 $\mathrm{g} \mathrm{NaNO}_{3}$ was added into the above mixture under stirring and cooling in an ice bath condition for $15 \mathrm{~min}$, followed by slowly adding $6 \mathrm{~g} \mathrm{KMnO}_{4}$. Then the mixture was continuously stirred overnight at room temperature, followed by adding $92 \mathrm{~mL}$ deionized water, $280 \mathrm{~mL}$ warm deionized water and $10 \mathrm{~mL} 30$ wt.\% $\mathrm{H} 2 \mathrm{O} 2$ in suquence. The obtained graphite oxide was then washed with 1:10 (v:v) $\mathrm{HCl}$ solution once and deionized water three times. The graphite oxide was collected by dried in a vacuum oven at $45{ }^{\circ} \mathrm{C}$ overnight. Graphene oxide (GO) was fabricated through heat treatment the graphite oxide at $450{ }^{\circ} \mathrm{C}$ for $5 \mathrm{~h}$, and then reduced graphene oxide (RGO) was obtained by heating $\mathrm{GO}$ at $750{ }^{\circ} \mathrm{C}$ for $5 \mathrm{~h}$. As in our previous report [16], the final S/RGO product was prepared by a melt-diffusion method at $155{ }^{\circ} \mathrm{C}$ for $12 \mathrm{~h}$ with the optimal weight ratio of sulfur : carbon $(60: 40)$ in a sealed Teflon container under air atmosphere, which is denoted thereafter as $0.6 \mathrm{~S} / \mathrm{RGO}$.

The samples were characterized by field-emission scanning electron microscope (FESEM; JEOL7500), powder X-ray diffraction (XRD; GBC MMA) with $\mathrm{Cu} \mathrm{K} \alpha$ radiation. The viscosity of electrolytes was measured by rotational viscometer (Fungilab alpha series V100002). The electrochemical tests were conducted by assembling coin-type half cells in an argon-filled glove box. Lithium foil was employed as both reference and counter electrode. The working electrode consisted of 70 wt \% $0.6 \mathrm{~S} / \mathrm{RGO}, 20 \mathrm{wt} \%$ carbon black and $10 \mathrm{wt} \%$ polyvinylidene fluoride 
(PVdF) and was prepared by homogeneously mixing for 8 minutes by planetary mixer (KK-250S). The obtained slurry was then pasted on an aluminum (Al) film by a doctor blade with the thickness of $100 \mu \mathrm{m}$ and then dried in an vacuum oven at $55^{\circ} \mathrm{C}$ for 12 h. The dried cathode film was punch into discs of $0.97 \mathrm{~cm}$ diameter. The electrodes were separated by a commercial separator material (Celgard 2400). The electrolytes were $1.0 \mathrm{M} \mathrm{LiN}\left(\mathrm{CF}_{3} \mathrm{SO}_{2}\right)_{2}$ (LiTFSI) in a $1: 1 \mathrm{v} / \mathrm{v}$ mixture of DME and DOL (DME/DOL), DME and DOL with $0.1 \mathrm{M} \mathrm{LiNO}_{3}\left(\mathrm{DME} / \mathrm{DOL}+\mathrm{LiNO}_{3}\right) ; 1.0 \mathrm{M}$

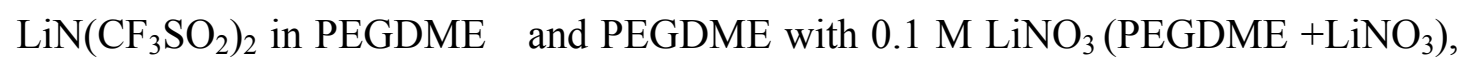
respectively. Charge and discharge curves were tested at $0.1 \mathrm{C}\left(1 \mathrm{C}=1680 \mathrm{~mA} \mathrm{~g}^{-1}\right)$ by galvanostatic measurements in the $1.5 \mathrm{~V}$ to $3.0 \mathrm{~V}$ voltage window (vs. $\mathrm{Li} / \mathrm{Li}^{+}$). Cyclic voltammetry was performed using a Biologic VMP-3 electrochemical workstation between 1.5-3.0 $\mathrm{V}$ at a scan rate of $0.1 \mathrm{mV} \mathrm{s}^{-1}$.

\section{Results and discussion}

The morphology of $0.6 \mathrm{~S} / \mathrm{RGO}$ was characterized by SEM images. There is no bulk crystalline sulfur observed at low magnification as in Fig. 1(a), indicating that a large amount of sulfur has been completely loaded into the RGO framework. The high-magnification image (Fig. 1b) shows that some sulfur nanoparticles agglomerate together and anchored on the surface of the RGO host. As shown in Fig. 1c, the RGO framework possesses ideal layer-by-layer structure and that there is no sulfur nanoparticles observed between the RGO layers at higher magnification. Such a structure not only effectively improves the electronic conductivity of sulfur. It can also avoid the large dissolution of lithium polysulfides by physically confining the 
sulfur within the matrix. The elemental mappings of sulfur and carbon in Fig. 1(d) further corroborate that the sulfur is homogeneously embedded into the framework of RGO host, which is ascribed to the favorable fluidity of molten sulfur. The SEM results indicate that there are two kind of sulfur including amorphous phase into the graphene nanosheets and crystalline nanoparticles on the surface in the $0.6 \mathrm{~S} / \mathrm{RGO}$ composite.

As shown clearly in Fig. 2, the XRD profile of RGO exhibits a broad weak (002) diffraction peak at $2 \theta$ of $26.4^{\circ}$, which is ascribed to disordered stacks of graphene nanosheets. In comparison with the pattern of pure sulfur, the XRD pattern of the 0.6S/RGO yields fewer peaks of sulfur with lower intensity and the broad (002) peak of RGO at same position $\left(2 \theta=26.4^{\circ}\right)$, which proves that the sulfur is mainly embeded into the RGO nanoframework and the rest of sulfur is anchored on the surface of the RGO host. Graphene nanosheets do not restack together upon the sulfur into RGO in the synthesis. The interlayer spacing/edges/defects within the RGO framwork as good containers of amorphous sulfur can confine sulfur and polysulfides in the framework, leading to good electrochemical properties. The XRD results further confirm the two states of sulfur in the composite, in agreement with the SEM results.

Cyclic voltammogram (CV) and charge/discharge curves of the $0.6 \mathrm{~S} / \mathrm{RGO}$ cathode in the two electrolytes are presented in Fig. 3. As shown in Fig.3(a), three cathodic peaks are observed at $2.45,2.05$, and $1.9 \mathrm{~V}$ during the discharge process, showing typical sulfur cathode charge/discharge behavior [14,24]. Firstly, elemental sulfur in the solid phase is dissolved in the electrolyte, and then it is reduced to $\mathrm{S}_{6}{ }^{2-}, \mathrm{S}_{4}{ }^{2-}$, and 
$\mathrm{S}_{2}{ }^{2-}\left(\mathrm{S}^{2-}\right)$, respectively. The high order lithium polysulfides are soluble, but the low order polysulfides are poorly soluble and insulating. Unlike the complex multistep discharge mechanism, one anodic peak at about $2.45 \mathrm{~V}$ is associated with the oxidation of $\mathrm{Li}_{2} \mathrm{~S}_{2}$ and $\mathrm{Li}_{2} \mathrm{~S}$ to long lithium polysulfide compounds $\left(\mathrm{Li}_{2} \mathrm{~S}_{\mathrm{n}}, \mathrm{n}>2\right)$. $\mathrm{Li}_{2} \mathrm{~S}_{2}$ and $\mathrm{Li}_{2} \mathrm{~S}$ cannot be fully converted into high order polysulfides because of their insulation and insolubility. The irreversible $\mathrm{Li}_{2} \mathrm{~S}_{2}$ and $\mathrm{Li}_{2} \mathrm{~S}$ left at the cathode after charging lead to active material loss and are responsible for irreversible capacity. During the following reduction process, the higher-potential peak and the lower-potential peak present good repeatability, however, the peak in the middle position becomes weaker and gradually disappears. It unambiguously pointed out that this peak is related to unstable intermediate species produced by the first redox process, which further proves that the Li-S battery discharge mechanism is complex and involves many intermediate compounds. We can speculate that the soluble intermediate products of lithium polysulfide $\left(\mathrm{Li}_{2} \mathrm{~S}_{\mathrm{n}}, 4 \leq \mathrm{n}<8\right)$ are a mixture of $\mathrm{Li}_{2} \mathrm{~S}_{6}$ and $\mathrm{Li}_{2} \mathrm{~S}_{4}$ during first cycles, while only $\mathrm{Li}_{2} \mathrm{~S}_{6}$ exists during the longer cycles before the generation of $\mathrm{Li}_{2} \mathrm{~S}_{\mathrm{n}}$ and $\mathrm{Li}_{2} \mathrm{~S}$. According to a previous report [25], the $\mathrm{Li}_{2} \mathrm{~S}_{6}$ is the most stable state of soluble lithium polysulfide that exists in electrolyte. This result proves that the multistep intermediate chemical reaction occurs rapidly in PEGDME electrolyte, so that high ordered lithium polysulfide $\left(\mathrm{Li}_{2} \mathrm{~S}_{8}\right.$ or $\left.\mathrm{S}\right)$ could be quickly reduced by lower ordered lithium polysulfide $\left(\mathrm{Li}_{2} \mathrm{~S}_{2}\right.$ or $\left.\mathrm{Li}_{2} \mathrm{~S}\right)$ or lithium to the particularly stable $\mathrm{S}_{6}{ }^{2-}$. With ongoing cycling, the solid residua $\left(\mathrm{Li}_{2} \mathrm{~S}_{2}\right.$ and $\left.\mathrm{Li}_{2} \mathrm{~S}\right)$ on the RGO matrix could be consumed, therefore, resulting in good capacity retention. 
For the DOL/DME-based electrolyte (Fig. 3(b)), obvious differences are found, implying that the sulfur cathode undergoes different chemical reaction processes. A low-voltage peak $(1.5 \mathrm{~V})$ can only be observed for the first cycle, which may be due to the solid-solid reaction process between the insoluble $\mathrm{Li}_{2} \mathrm{~S}_{2}$ and $\mathrm{Li}_{2} \mathrm{~S}$ [22]. This process is kinetically slow and normally suffers high polarization, owing to the insulating nature of $\mathrm{Li}_{2} \mathrm{~S}_{2}$ and $\mathrm{Li}_{2} \mathrm{~S}$. Then only two high-voltage peaks appear during the following cycles, which is consistent with the two plateau reduction process often reported in the literatures $[5,6,12,16]$. The cathodic peaks around $2.3 \mathrm{~V}$ and $2.0 \mathrm{~V}$ correspond to the two steps of the reduction of sulfur and lithium. The $2.3 \mathrm{~V}$ peak is related to the formation of high order lithium polysulfides $\left(\mathrm{Li}_{2} \mathrm{~S}_{\mathrm{n}}, \mathrm{n} \geq 4\right)$, The $2.0 \mathrm{~V}$ peak is caused by the reduction of high order polysulfides to low order polysulfides $\left(\mathrm{Li}_{2} \mathrm{~S}_{2}\right.$ or $\left.\mathrm{Li}_{2} \mathrm{~S}\right)$. The $\mathrm{CV}$ results are further confirmed by the corresponding charge/discharge curves. The different electrochemical processes that involve the S/RGO composite in the two electrolytes may be attributed to the different types of dissolution of the sulfur and polysulfide in the electrolytes with different viscosity. The $\mathrm{DOL} / \mathrm{DME}+\mathrm{LiNO}_{3}$ electrolyte with lower viscosity $(1.10 \mathrm{mPa} \cdot \mathrm{s})$ is supposed to dissolve the active material more easily. High ordered lithium polysulfide existed in the electrolyte is difficult to transform completely from liquid phase to solid phase at the end of discharge process, leading to higher capacity but rapid capacity fading. In contrast, the active materials are dissolved appropriately in the $\mathrm{PEGDME}+\mathrm{LiNO}_{3}$ electrolyte with higher viscosity $(25.75 \mathrm{mPa} \cdot \mathrm{s})$, which can ensure good cycling stability and high capacity as well. 
It can be seen that both electrodes undergo capacity fading during the first few cycles from Fig. 3(c) and 3(d), which is mostly associated with the dissolution of active materials into the electrolyte systems. Furthermore, the initial discharge capacity is higher, which results from the formation of the solid electrolyte interphace (SEI) film, the presence of oxidant on the RGO and the associated electrolyte decomposition [26]. As shown in Fig. 3(c), three discharge platforms and one charge platform are observed in the initial cycles with PEGDME-based electrolyte. And then the second discharge platform disappears after the second cycle, which is consistent with the corresponding CV curves. During the 200 cycles, the first plateau is always stable, while the third plateau decreases gradually. This indicates the precipitation of isolated and irreversible $\mathrm{Li}_{2} \mathrm{~S}$ and $\mathrm{Li}_{2} \mathrm{~S}_{2}$ on the cathode leading to the capacity decay. For the sample in DOL/DME-based electrolyte, both the discharge plateaus quickly become shorter and shorter during the 200 cycles, which indicates severe loss of active materials. The obvious capacity decay during the charge/discharge process is mainly responsible for the dissolution of active material in the electrolyte and its disintegration from the RGO matrix, eventually causing rapid capacity fading.

The $0.6 \mathrm{~S} / \mathrm{RGO}$ electrodes were tested in the two electrolytes, and in the electrolytes without $\mathrm{LiNO}_{3}$ additive for comparison (Fig. 4(a)). The $0.6 \mathrm{~S} / \mathrm{RGO}$ cathode with PEGDME-based electrolyte showed better cycling stability and higher reversible capacity than the one with DOLDME electrolyte. It is evident that the addition of $\mathrm{LiNO}_{3}$ to the electrolytes could dramatically relieve the overcharge phenomenon, with cycling stability and reversible capacities similar to that of the 
samples without $\mathrm{LiNO}_{3}$ additives. A high initial capacity of $1290.1 \mathrm{mAh} \mathrm{g}-1$ is achieved with coulombic efficiency of $93.3 \%$ and a rapid capacity drop during the first few cycles and good stability on subsequent cycles are observed for $0.6 \mathrm{~S} / \mathrm{RGO}$ with PEGDME+LiNO3 electrolyte. The capacity rapidly decreases to $896.1 \mathrm{mAh} \mathrm{g}^{-1}$ after 15 cycles, and then is slightly reduced to $624.8 \mathrm{mAh} \mathrm{g}^{-1}$ after 200 cycles, yielding retention of $52 \%$ of initial charge capacity. The high charge capacity of $548.8 \mathrm{mAh} \mathrm{g}^{-1}$ can be obtained after 300 cycles for the sample in the PEGDME with $\mathrm{LiNO}_{3}$ additive. The sample in $\mathrm{DOL} / \mathrm{DME}+\mathrm{LiNO}_{3}$ electrolyte delivers a first capacity as high as $1275 \mathrm{mAh} \mathrm{g}^{-1}$, however, only $57.8 \mathrm{mAh} \mathrm{g}^{-1}$ of the charge capacity is retained after 300 cycles. To better investigate the function of the $\mathrm{LiNO}_{3}$ additive, the Coulombic efficiency of the $0.6 \mathrm{~S} / \mathrm{RGO}$ cathode in various electrolytes is depicted in Fig. 4(b). It is well known that $\mathrm{LiNO}_{3}$ in the electrolyte is favorable to form an in-situ passivation film on the lithium electrode, preventing polysulfides in the electrolyte from directly reacting with the lithium metal and thus reduce the shuttle effect [21-23]. The average Coulombic efficiency of the $0.6 \mathrm{~S} / \mathrm{RGO}$ cathode (100 cycles) increases significantly from $85.2 \%$ (PEGDME) to $98.8 \%$ (PEGDME $+\mathrm{LiNO}_{3}$ ) and from $82.6 \%(\mathrm{DOL} / \mathrm{DME})$ to $102.8 \%\left(\mathrm{DOL} / \mathrm{DME}+\mathrm{LiNO}_{3}\right)$, respectively. The results point out that $\mathrm{LiNO}_{3}$ could migrate quickly in low-viscosity DOL/DME electrolyte and be reduced to rapidly form an in-situ $\mathrm{Li}_{\mathrm{x}} \mathrm{NO}_{\mathrm{y}}$ protective film, thus completely eliminating the detrimental overcharge phenomenon [21-23]. However, the migration of $\mathrm{LiNO}_{3}$ in high-viscosity PEGDME might be slower, however, and thus only hinder the overcharge effect. The viscosity of PEGDME+ $\mathrm{LiNO}_{3}$ electrolyte is much higher 23 
times than $\mathrm{DOL} / \mathrm{DME}+\mathrm{LiNO}_{3}$ electrolyte from the experimental results, which further confirms the different migration ability of $\mathrm{LiNO}_{3}$. To compare the electrochemical properties in this work to those with similar components reported in the literature $[6,10,27-30]$, the results for various S/graphene cathodes are summarized in Table 1. It is obvious that the electrode in this work shows higher reversible capacity, higher Coulombic efficiency and better cycling stability as well than that from other works. This superior performance is mainly attributed to the architecture of $0.6 \mathrm{~S} / \mathrm{RGO}$, the presence of a suitable electrolyte, and the effects of $\mathrm{LiNO}_{3}$ additive.

Moreover, an excellent rate capability is achieved for the cathode in PEGDME $+\mathrm{LiNO}_{3}$ electrolyte. As shown in Fig. 5, the capacity decreases rapidly in the initial 15 cycles. It can be seen that the capacity then decreases gradually with the rapid increase of the charge-discharge current density. Even at the current density of 2 $\mathrm{C}$, the discharge capacity is still as high as about $330 \mathrm{mAh} \mathrm{g}^{-1}$. When the current density directly returns to the initial value of $0.1 \mathrm{C}$ after 30 cycles, the capacity recovers to $871.8 \mathrm{mAh} \mathrm{g}^{-1}$, which is equivalent to the value at the $30^{\text {th }}$ cycle shown in Fig. 3(a). The good rate capability is ascribed to the multifunction of RGO, On the one hand, The high surface area and ultra thinness of RGO nanosheets are helpful for accessibility of the electrolyte and rapid diffusion of lithium ions ingress/egress to react with the sulfur; On the other hand, graphene layers can act as mini-current collectors which facilitate the fast transportation of electrons during the charge-discharge process, resulting in the excellent rate behavior of the electrode.

Electrochemical impedance spectroscopy (EIS) measurements were carried out to 
compare the impedance differences of $0.6 \mathrm{~S} / \mathrm{RGO}$ cathode in these electrolytes. The data were collected from $100 \mathrm{KHz}$ to $20 \mathrm{mHz}$ on the coin-cell batteries after charge/discharge for 5 cycles. The intercept at real axis $Z^{\prime}$ is associated with the ionic resistance of the electrolyte, the intrinsic resistance of the active materials and the contact resistance at the active material/current collector interface, corresponding to the combination resistance $\left(\mathrm{R}_{\Omega}\right)$. The high frequency semicircle relates to Li-ion migration through the SEI films $\left(\mathrm{R}_{\mathrm{SEI}}\right)$, and the medium frequency semicircle is corresponding to the charge transfer resistance $\left(\mathrm{R}_{\mathrm{ct}}\right)[10,16]$. As shown in Fig. 6 , the Nyquist plots were fitted by an equivalent circuit consisting of $R_{\Omega}$ in series to a parallel circuit element that branches into $\mathrm{R}_{\mathrm{SEI}}$ and CPE1 then another parallel circuit element that branches into Rct with $\mathrm{W}$ and the double layer capacitance (CPE2).The calculated values according to this model circuit are presented in Table 2 . The $R_{\Omega}$ of electrodes with DOL/DME (2.4 $\Omega$ ) and DOL/DME+LiNO $3(3.4 \Omega)$ are much lower than the PEGDME (18.3 $\Omega$ ) and PEGDME+LiNO $3(12.1 \Omega)$. It demonstrates that the ionic resistance of the DOL/DME electrolyte is lower than the PEGDME electrolyte, probably ascribed to the lower viscosity of the DOL/DME electrolyte. $\mathrm{R}_{\mathrm{SEI}}$ of the cathodes slightly decrease due to the addition of $\mathrm{LiNO}_{3}$, which results from the passive film formed on the surface of lithium, protecting the lithium from further corrosion in the electrolyte, therefore, forming thinner SEI films than those without $\mathrm{LiNO}_{3}$ [21]. Rct of the cathodes are calculated to be $594.6 \Omega, 62 \Omega, 602.0 \Omega$ and $376.9 \Omega$ in DOL/DME, DOL/DME $+\mathrm{LiNO}_{3}, \mathrm{PEGDME}$, and PEGDME+LiNO electrolytes, respectively. It represents that the kinetic resistance of the charge transfer 
is much higher for PEGDME-based electrolyte, indicating that the high viscosity of electrolyte would decrease the electrochemical kinetics of the cathode, which is consistent with the $\mathrm{CV}$ results and electrochemical performances. It is noteworthy that the addition of $\mathrm{LiNO}_{3}$ leads to a lower Rct in both the electrolytes, indicating $\mathrm{LiNO}_{3}$ additive could obviously increase the ionic conductivity of the electrolytes as well.

\section{Conclusions}

This study has clarified that the electrolyte is crucial to the discharge mechanism of the Li/S battery. A "glyme" family solvent, PEGDME, enables the active material to be properly dissolved, showing a possible mechanism for sulfur reduction that consists of three steps. The DOL/DME solvent is proposed to excessively dissolve the active material, presenting a typical two-step reduction process and leading to abundant irreversible active materials loss. It is worth noting that the $\mathrm{LiNO}_{3}$ additive also shows different inhibiting effects towards shuttle mechanism with different electrolytes, which are probably related to the viscosity of electrolyte. These results indicate that the discharge mechanism of the Li-S battery is quite complicated and involves many intermediate compounds. The results also can promote a better understand the multistep mechanism in specific investigated systems, including those PEGDME-based and DOL/DME-based electrolytes.

\section{Acknowledgments}

This work is supported by the Australian Research Council through a Discovery Project (DP110103909). The authors would like to also thank Dr Tania Silver for 
critical reading of the manuscript. 


\section{References}

[1] J. B. Goodenough, Y. Kim, Chem. Mater. 22 (2010) 587-603.

[2] A. S. Arico, P. G. Bruce, B. Scrosati, J. Tarascon, W. V. Schalkwijk, Nat. Mater. 4 (2005) 366-377.

[3] P. G. Bruce, B. Scrosati, J. Tarascon, J. Angew. Chem., Int. Ed.47 (2008) 2930-2946.

[4] M. Armand, J. M. Tarascon, Nature. 451 (2008) 652-657.

[5] J. Schuster, G. He, B. Mandlmeier, T. Yim, K. T. Lee, T. Bein and L. F. Nazar, J. Angew. Chem., Int. Ed. 51 (2012) 3591-3595.

[6] H. Wang, Y. Yang, Y. Liang, J. T. Robinson, Y. Li, A. Jackson, Y. Cui and H. Dai, Nano Lett. 11 (2011) 2644-2647.

[7] B. L. Ellis, K. T. Lee, L. F. Nazar, Chem. Mater. 22 (2010) 691-714.

[8] B. Zhang, X. Qin, G. R. Li, X. P. Gao, Energy Environ. Sci. 3 (2010) $1531-1537$.

[9] H. S. Ryu, Z. Guo, H. J. Ahn, G. B. Cho, H. Liu, J. Power Sources 189 (2009) $1179-1183$

[10] J. Wang, L. Lu, M. Choucair, J. A. Stride, X. Xu, H. Liu, J. Power Sources 196 (2011) 7030-7034.

[11] Y. M. Lee, N. S. Choi, J. H. Park, J. K. Park, J. Power Sources 119 (2003) 964-972.

[12] Y. V. Mikhaylik, J. R. Akridge, J. Electrochem. Soc. 151 (2004) A1969-A1976. 
[13] W. Zheng, Y. W. Liu, X. G. Hu, C. F. Zhang, Electrochim. Acta 51 (2006) $1330-1335$.

[14] J. Guo, Y. Xu, and C. Wang, Nano Lett. 11 (2011) 4288-4294.

[15] G. Y. Zheng, Y. Yang, J. J. Cha, S. S. Hong, and Y. Cui, Nano Lett. 11 (2011) $4462-4467$.

[16] Y.-X. Wang, L. Huang, L.-C. Sun, S.-Y. Xie, G.-L. Xu, S.-R. Chen, Y.-F. Xu, J.-T. Li, S.-L. Chou, S.-X. Dou and S.-G. Sun, J. Mater. Chem. 22 (2012) $4744-4450$.

[17] W. Hummers, R. Offeman, J. Am. Chem. Soc. 80 (1958) 1339.

[18] K. Kumaresan, Y. Mikhaylik, R. E. White, J. Electrochem. Soc. 155 (2008) A576-A582

[19] J. R. Akridge, Y. V. Mikhaylik, N. White, Solid State Ionics 175 (2004) $243-245$.

[20] Y. V. Mikhaylik, J. R. Akridge, J. Electrochem. Soc. 151 (2004) A1969-A1976.

[21] X. Liang, Z. Wen, Y. Liu, M. Wu, J. Jin, H. Zhang, X. Wu, J. Power Sources 196 (2011) 9839-9843.

[22] S. S. Zhang, Electrochimica Acta 70 (2012) 344-348.

[23] D. Aurbach, E. Pollak, R. Elazari, G. Salitra, C. S. Kelley, and J. Affinito, J. Electrochem. Soc. 156 (2009) A694-A702.

[24] C. Barchasz, F. Molton, C. Duboc, J.-C. Lepretre, S. Patoux, and F. Alloin, Analytical Chemistry, 84 (2012) 3937-3980. 
[25] Y. Diao, K. Xie, S. Xiong, and X. Hong, J. Electrochem. Soc. 159 (2012) A421-A425.

[26] S. Joongpyo, K. A. Striebel, E. J. Cairns, J. Electrochem. Soc. 149 (2002) A1321-A1325.

[27] S. Evers and L. F. Nazar, Chem. Commun. 48 (2012) 1233-1235.

[28] Y. Cao, X. Li, I. A. Aksay, J. Lemmon, Z. Nie, Z. Yang and J. Liu, Phys. Chem. Chem. Phys. 13 (2011) 7660-7665.

[29] M.-S. Park, J.-S. Yu, K. J. Kim, G. Jeong, J.-H. Kim, Y.-N. Jo, U. Hwang, S. Kang, T. Woo and Y. J. Kim, Phys. Chem. Chem. Phys. 14 (2012) 6796-6804.

[30] N. Li, M. Zheng, H. Lu, Z. Hu, C. Shen, X. Chang, G. Ji, J. Cao and Y. Shi, Chem. Commun. 48 (2012) 4106-4108. 


\section{Figure captions:}

Fig. 1. FESEM images of the $0.6 \mathrm{~S} / \mathrm{RGO}$ powders at low magnification (a), high magnification (b) (c), and elemental mappings of carbon and sulfur in the insets (d).

Fig. 2. XRD patterns of $\mathrm{S}, 0.6 \mathrm{~S} / \mathrm{RGO}$ and $\mathrm{RGO}$.

Fig. 3. Cyclic voltammograms of $0.6 \mathrm{~S} / \mathrm{RGO}$ in coin cells at the scan rate of $0.05 \mathrm{mV}$ $\mathrm{s}^{-1}$ with $\mathrm{PEGDME}+\mathrm{LiNO}_{3}$ electrolyte (a), and $\mathrm{DOL} / \mathrm{DME}+\mathrm{LiNO}_{3}$ electrolyte (b); charge/discharge profiles of selected cycles of the $0.6 \mathrm{~S} / \mathrm{RGO}$ at $0.1 \mathrm{C}$ in PEGDME $+\mathrm{LiNO}_{3}$ electrolyte (c), and DOL/DME $+\mathrm{LiNO}_{3}$ electrolyte (d).

Fig. 4. (a) Cycling performance and (b) Coulombic efficiency of $0.6 \mathrm{~S} / \mathrm{RGO}$ at $0.1 \mathrm{C}$ in various electrolytes;

Fig. 5. Cycling performance of the $0.6 \mathrm{~S} / \mathrm{RGO}$ in $\mathrm{PEGDME}+\mathrm{LiNO}_{3}$ electrolyte cycled at different current rate.

Fig. 6. Impedance plots of $0.6 \mathrm{~S} / \mathrm{RGO}$ collected from $100 \mathrm{KHz}$ to $30 \mathrm{mHz}$ in various electrolytes. 
Table 1. Comparison of the electrochemical properties of $\mathrm{S} /$ graphene cathodes prepared in this work with previous works.

\begin{tabular}{cccccc}
\hline Reference & $\begin{array}{c}\text { Sulfur } \\
\text { content } \\
(\mathrm{wt} \%)\end{array}$ & $\begin{array}{c}\text { Current } \\
\text { density } \\
(\mathrm{C} \text { rate })\end{array}$ & $\begin{array}{c}\text { Initial } \\
\text { discharge/charge } \\
\text { capacity } \\
\left(\mathrm{mAh} \mathrm{g}^{-1}\right)\end{array}$ & $\begin{array}{c}\text { Average } \\
\text { Coulombic } \\
\text { efficiency } \\
(\%)\end{array}$ & $\begin{array}{c}\text { Capacity } \\
\text { retention } \\
\left(\mathrm{mAh} \mathrm{g}^{-1}\right)\end{array}$ \\
\hline This work & $60 \%$ & $0.1 \mathrm{C}$ & $1290 / 1203$ & $98 \%$ & $\begin{array}{c}625(200 \\
\text { cycles })\end{array}$ \\
{$[6]$} & $\sim 70 \%$ & $0.2 \mathrm{C}$ & $\sim 620 / 750$ & No data & $\begin{array}{c}\sim 600(100 \\
\text { ycles })\end{array}$ \\
{$[10]$} & $\sim 22 \%$ & $0.06 \mathrm{C}$ & $1611 / 1700$ & No data & $\begin{array}{c}\sim 520(40 \\
\text { cycles })\end{array}$ \\
{$[27]$} & $87 \%$ & $0.2 \mathrm{C}$ & $705 / 690$ & $\sim 93 \%$ & $\begin{array}{c}\sim 550(50 \\
\text { cycles })\end{array}$ \\
{$[28]$} & $\sim 71.8 \%$ & $0.1 \mathrm{C}$ & $950 / \sim 960$ & No data & $\begin{array}{c}\sim 760(50 \\
\text { cycles })\end{array}$ \\
{$[29]$} & $83.30 \%$ & $0.1 \mathrm{C}$ & $1237 / 1222$ & No data & $\begin{array}{c}829.8(50 \\
\text { cycle }) \\
930]\end{array}$ \\
& $63 \%$ & $0.12 \mathrm{C}$ & $\sim 1600 / \sim 1300$ & $>93 \%$ & $\begin{array}{c}928(100 \\
\text { cycle })\end{array}$ \\
\hline
\end{tabular}


Table 2. Resistance of equivalent circuit elements from the impedance scans with various electrolyte of $0.6 \mathrm{~S} / \mathrm{RGO}$.

\begin{tabular}{|c|c|c|c|c|}
\hline Electrolyte & DOL/DME & $\begin{array}{c}\mathrm{DOL} / \mathrm{DME} \\
+\mathrm{LiNO}_{3}\end{array}$ & PEGDME & $\begin{array}{l}\text { PEGDME } \\
+\mathrm{LiNO}_{3}\end{array}$ \\
\hline $\mathrm{R}_{\Omega}(\Omega)$ & 2.4 & 3.4 & 18.3 & 12.1 \\
\hline $\mathrm{R}_{\mathrm{SEI}}(\Omega)$ & 235.0 & 225.9 & 111.0 & 78.3 \\
\hline $\operatorname{Rct}(\Omega)$ & 594.6 & 62.0 & 602.0 & 376.9 \\
\hline
\end{tabular}



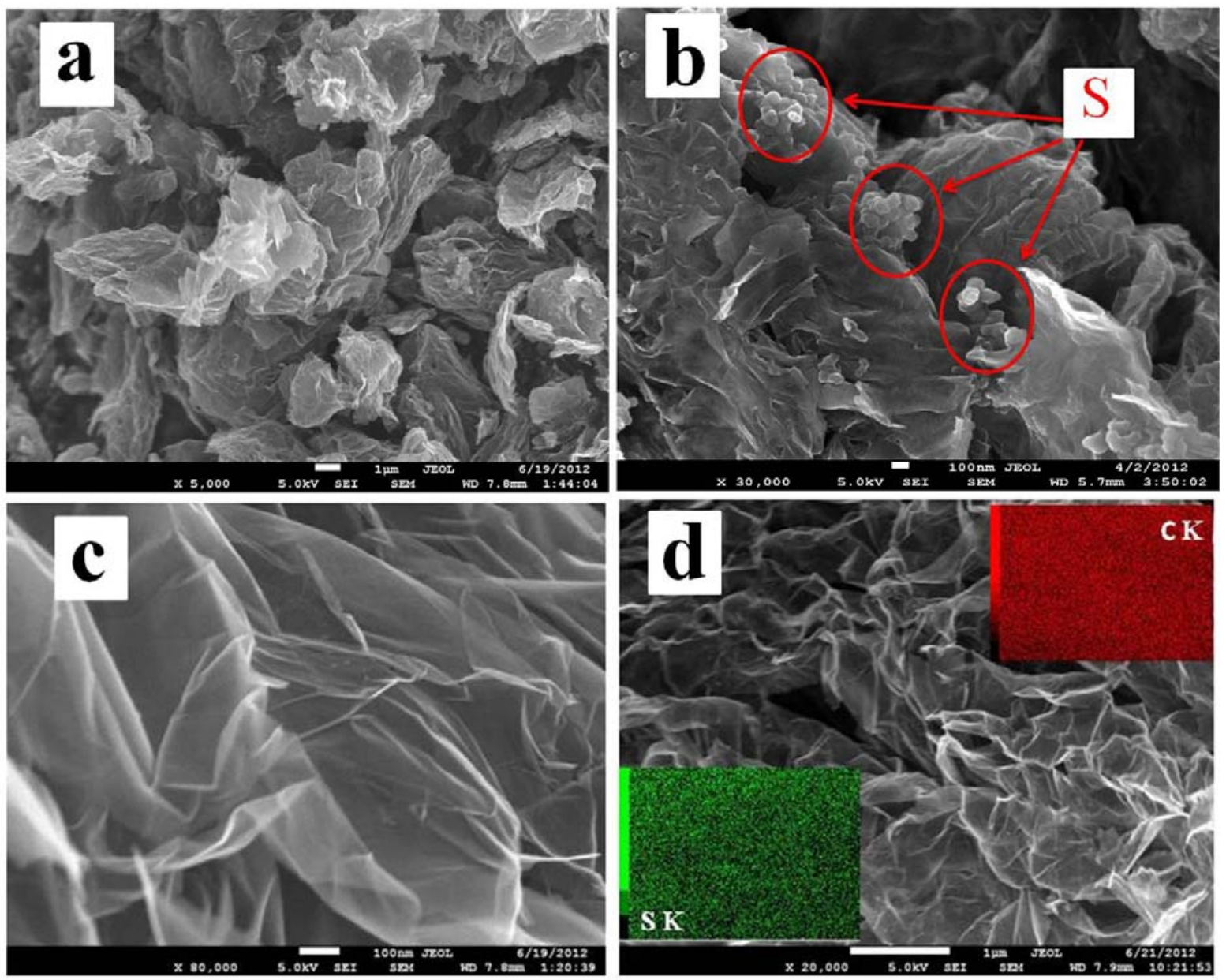

Fig.1 


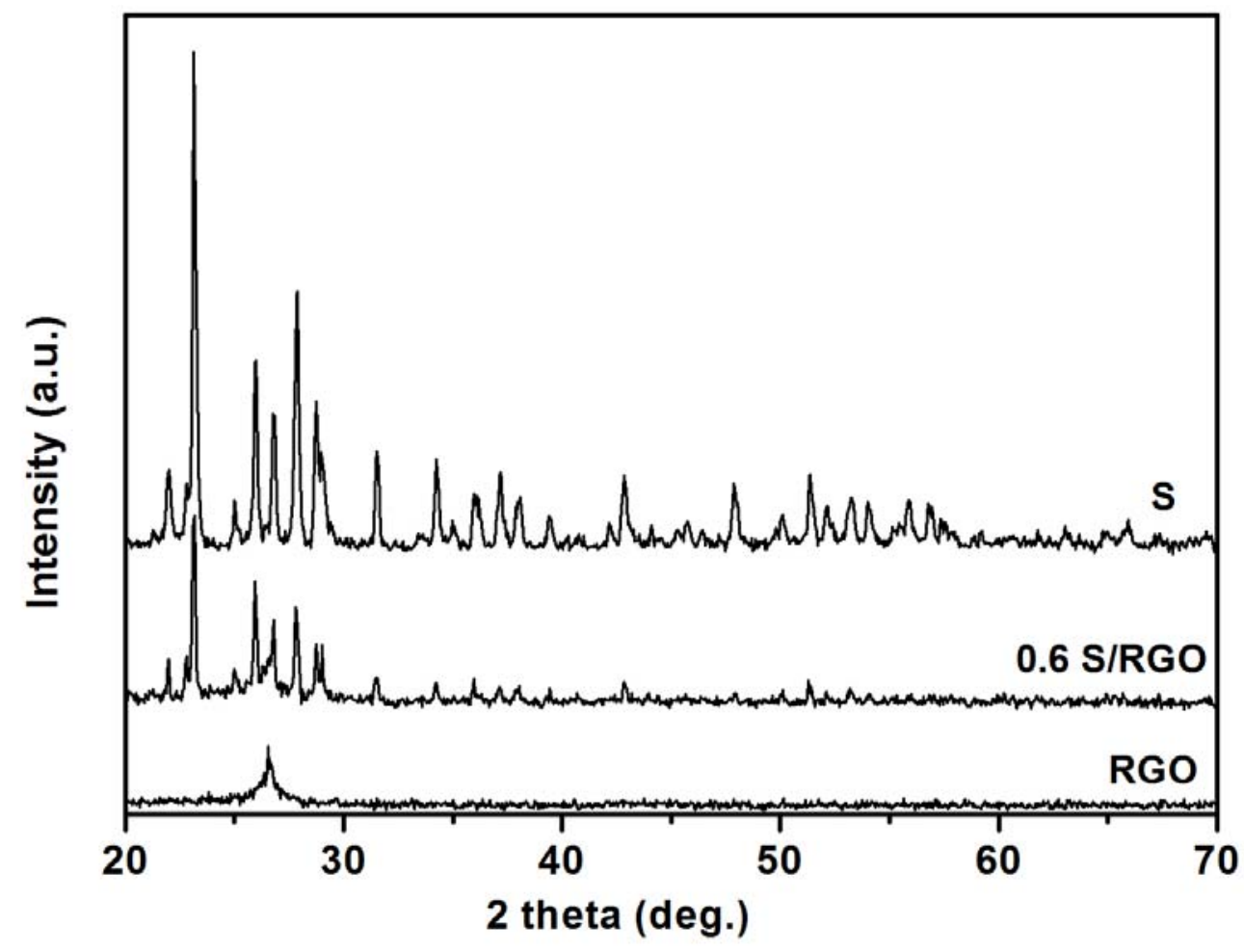

Fig. 2 

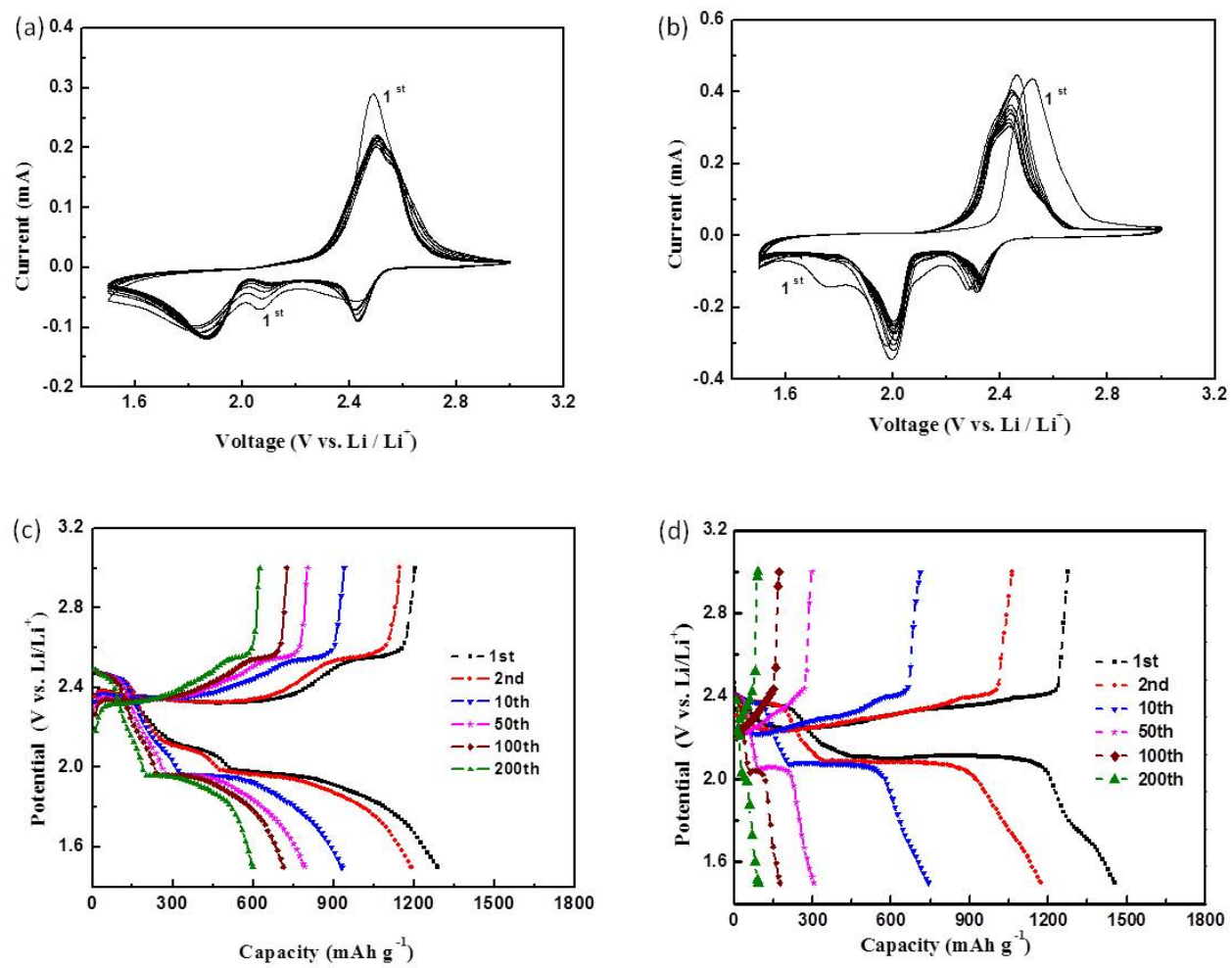

Fig.3 

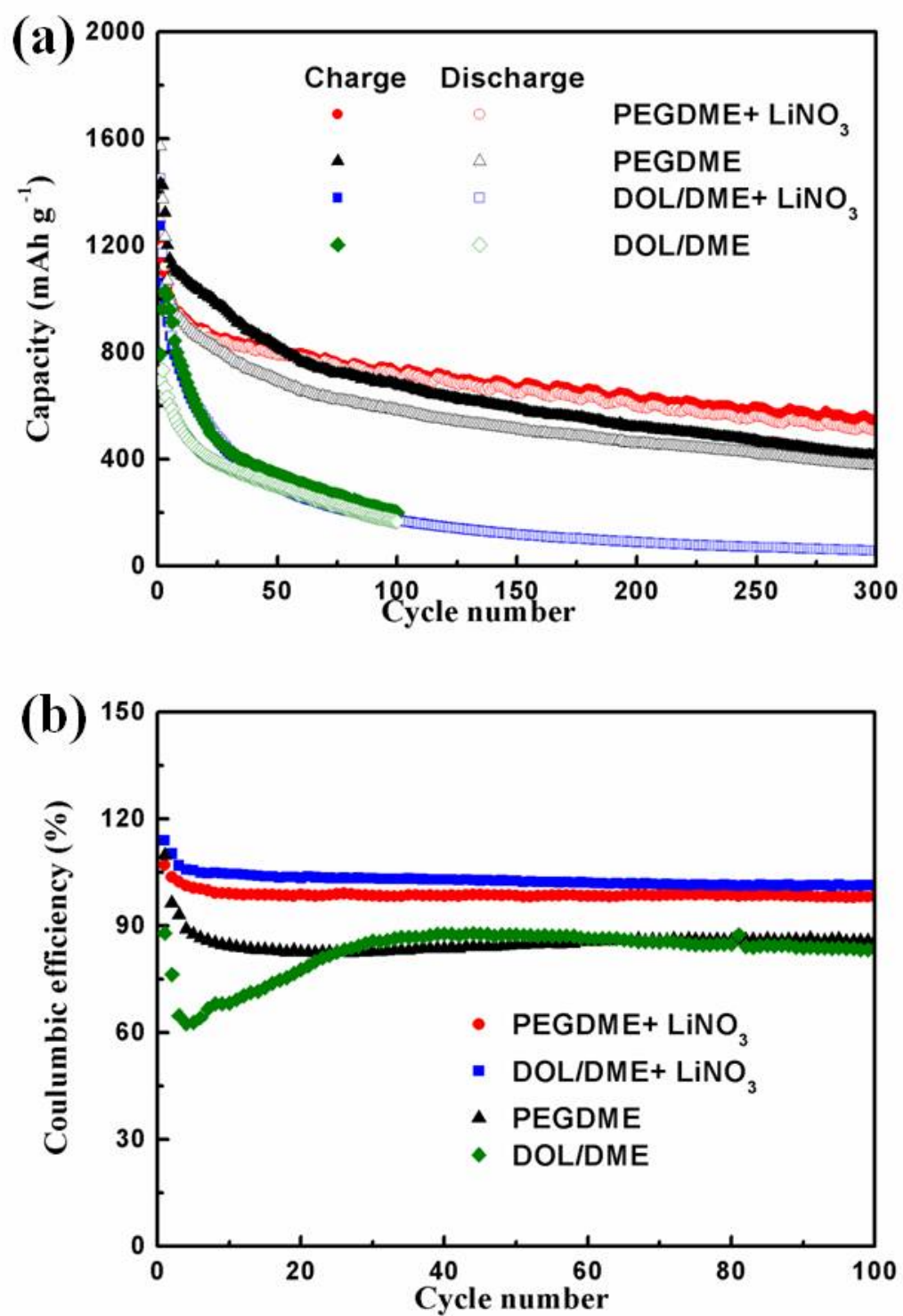

Fig.4 


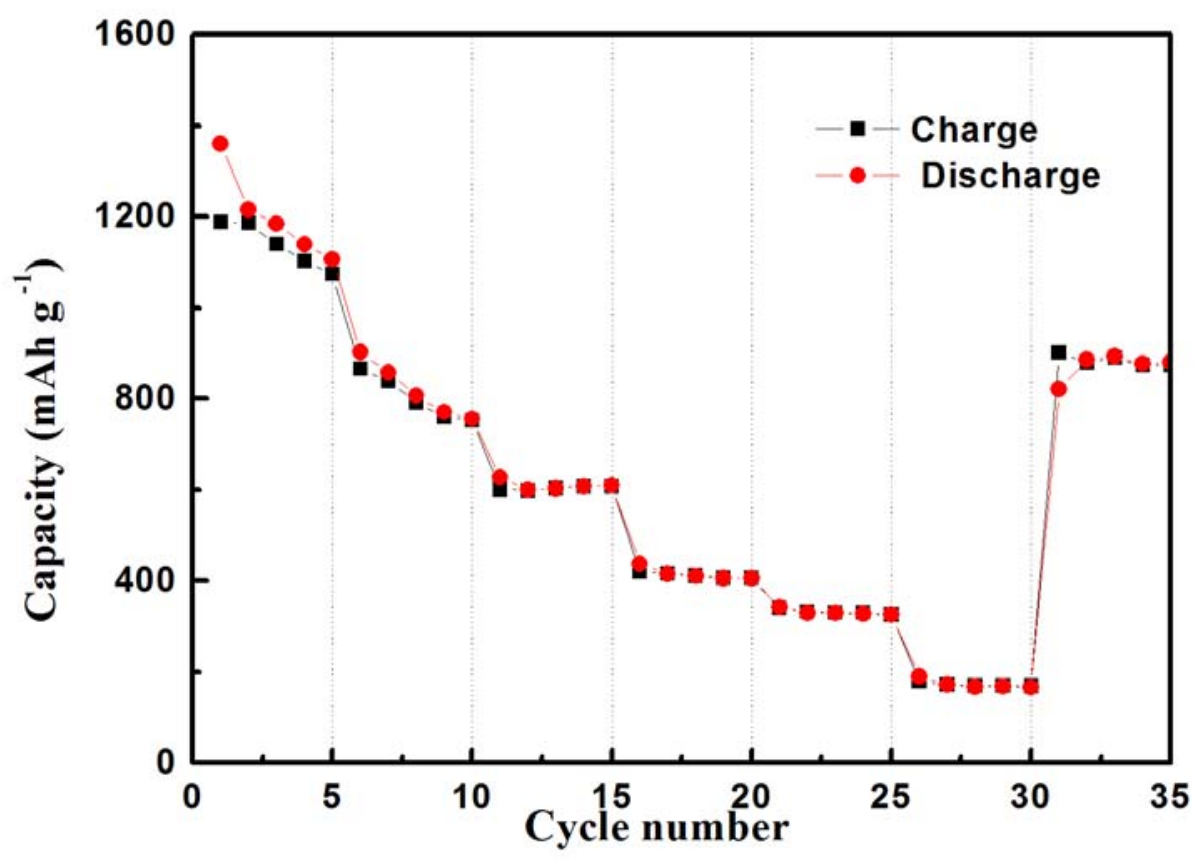

Fig. 5 


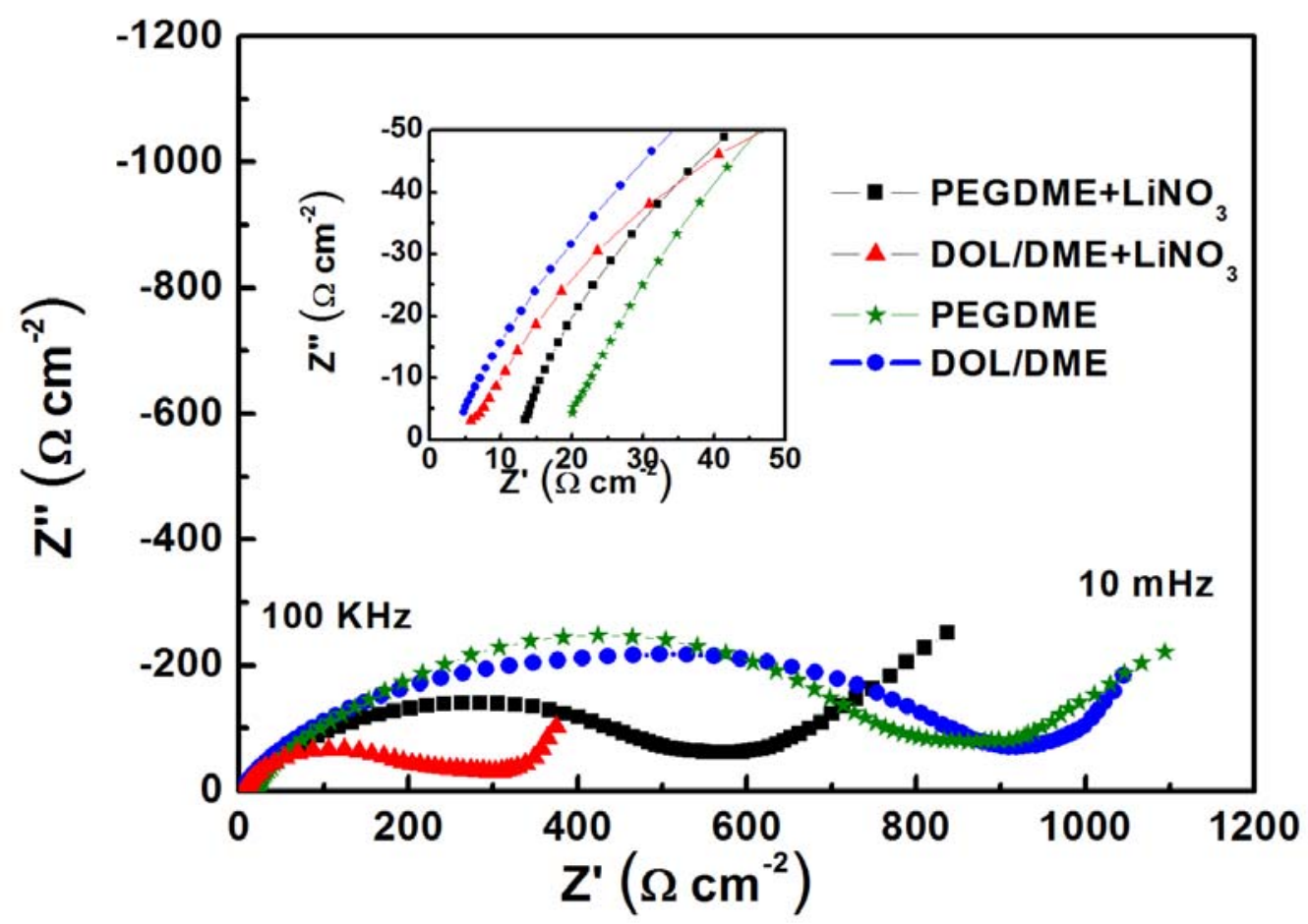

Fig.6 